\title{
Antennal sensilla in female Heterobathmia pseuderiocrania (Insecta, Lepidoptera, Heterobathmiina)
}

\author{
Michel J. FAUCHEUX
}

\begin{abstract}
Laboratoire d'Endocrinologie des Insectes Sociaux, Faculté des Sciences et des Techniques, 2 rue de la Houssinière, B.P. 92208, 44322 Nantes Cedex 3, France. joseph.baudet@isomer.univ-nantes.fr
\end{abstract}

\begin{abstract}
The female antennae of Heterobathmia pseuderiocrania bear 9 types or subtypes of sensilla: multiporous sensilla trichodea of subtypes I and II, multiporous sensilla basiconica, multiporous sensilla auricillica of subtypes I and II, multiporous sensilla coeloconica, uniporous sensilla basiconica, uniporous sensilla chaetica, aporous Böhm's bristles. Aporous sensilla styloconica are not observed. During evolution of Lepidoptera, it is in the suborder Heterobathmina that typical sensilla auricillica appear for the first time. Moreover, it is the first description in Lepidoptera, on the one hand of two very different subtypes of sensilla auricillica in the same species and, on the other hand, of a sexual dimorphism related to one subtype of these sensilla. The sensory structures are compared with those of the three other suborders of Lepidoptera. The Heterobathmiina do not possess the specialized sensillar types which occur in the basal suborders Zeugloptera and Aglossata. They have three possible autapomorphies which concern the sensilla auricillica. Their sensilla are close to those of the suborder Glossata which group together all the higher lepidopterans.
\end{abstract}

Key words: Lepidoptera, Heterobathmia, antenna, sensilla.

The Lepidoptera must be grouped into four suborders: Zeugloptera (the family Micropterigidae only), Aglossata (the family Agathiphagidae only), Heterobathmina (the family Heterobathmiidae only), Glossata (all other families) (Kristensen, 1984). The currently best supported phylogeny of the basal lepidopteran clades is Zeugloptera + (Aglossata + (Heterobathmina + Glossata)) (Kristensen, 1997). In comparison with " higher " Lepidoptera (Glossata), which often have an economic interest, little is known about the types and structure of antennal sensilla of "lower " Lepidoptera (review in Faucheux, 1999). However, the latter have a great importance in phylogenetic reasoning (Nieukerken \& Dop, 1987).

Some observations have been published in taxonomic papers; interesting as they are, they give an incomplete idea of the antennal sensory equipment (Kristensen, 1984; Kristensen \& Nielsen 1979,1982$)$. Detailed studies of the Zeugloptera and Aglossata have been carried out (Faucheux, 1990a; 1997b). Of the 12 sensillar types occurring in Micropterix calthella (Zeugloptera), seven are found in most higher Lepidoptera: sensilla trichodea, multiporous sensilla basiconica, sensilla coeloconica, sensilla styloconica, sensilla chaetica, sensilla campaniformia, and Böhm's bristles. Two types (uniporous sensilla basiconica and cupuliform organs) are found only in a few families. Three structures are peculiar to Micropterix: ascoid sensilla, multiporous sensilla placodea and circular organs (Faucheux 1997b). In Agathiphaga sp. (Aglossata), 10 types of sensilla are observed: Böhm's bristles, two types of sensilla chaetica, sensilla squamiformia, sensilla trichodea, biforked sensilla basiconica, short sensilla basiconica, and three types of sensilla coeloconica. Biforked sensilla basiconica are an autapomorphy of the Aglossata (Faucheux, 1990a). The object of the present paper is to determine in Heterobathmia pseuderiocrania, the specificity of the antennal sensory structures of the suborder Heterobathmina as compared with the two basal suborders and that of its sister-group, the subor. der Glossata.

\section{MATERIAL AND METHODS}

The moths Heterobathmia pseuderiocrania Kristensen \& Nielsen 1979 were provided by the Australian National Insect Collection (A.N.I.C.), Division of Entomology, CSIRO, Canberra, Australia, thanks to Dr E.S. Nielsen. They have been collected at San Martín de los Andes, altitude 640 
$\mathrm{m}$, Province of Neuquén, Argentine Patagonia, 29 9-1981, by E. S. Nielsen and O. Karsholt. For the study with scanning electron microscopy (SEM), the female antennae were dehydrated in absolute ethanol, mounted on specimen holders and coated with a thin layer of gold and palladium in a JFC 1100 sputter coater. Preparations were examined in a. JEOL JSM 6400 SEM at different magnifications. The terminology of Schneider (1964), Jefferson et al. (1970) and Zacharuk (1985) are used in naming the types of sensilla. The mean number of each sensillar type were calculated from the counts on every $5^{\text {th }}$ flagellomere with SEM, and expressed as mean $+/-\mathrm{SD}$.

\section{RESULTS}

The female antenna of $H$. pseuderiocrania reaches about the middle of the forewing costa. It consists of a large scape, a pedicel and a filiform. flagellum composed of 28 flagellomeres which are longer than wide. A covering of piliform scales is arranged in distinctly delimited groups on the scape, the pedicel and, in small numbers on the first flagellomeres. They are from two to four times longer than lamellar scales; some of them, inserted at the base of the scape, reach the $1^{\text {st }}$ flagellomere. The piliform scales on the scape cover the lamellar scales and are flattened (on the inner side) or erect (on the outer side). Transient forms between lamellar and piliform scales exist on the scape. Lamellar scales cover only the dorsal face of the flagellum (Figs. 1, 17), which possesses only a few sensilla chaetica, while the unscaled ventral face possesses the majority of sensilla.

Except for the dorsal scales, numerous noninnervated microtrichia, the spinules, emerge between the sensillar hairs and pegs (Figs. 1, 3), Very long, from 6 to $8 \mu \mathrm{m}$, they may easily be confused with short sensilla trichodea but are distinguished from the latter by (i) the absence of annular ridges, (ii) the absence of wall pores, (iii) their distribution on all the antennal segments, including the scape and the pedicel, (iv) and above all by their great number. Indeed, when counting spinules and sensilla with SEM, we found that over most of the ventral antennal surface, the number of spinules was 4 times that of sensilla.

The sensory structures comprise 9 types or subtypes of sensilla (s.): multiporous s. trichodea subtypes I and II, multiporous s. coeloconica, uniporous s. chaetica, uniporous short s. basiconica, multiporous long s. basiconica, multiporous s, auricillica subtypes I and II, Böhm's bristles. All these sensilla are located on the ventral face of the flagellum except Böhm's bristles situated on the scape and pedicel, and s. chaetica present all around the flagellum.

\section{Multiporous sensilla trichodea subtype I}

Based on the fine structure of the hairs, the sensilla trichodea can be divided into morphological subtypes I and II.

The sensilla trichodea I are long sensilla (Table 1) curved at their tip and slender; their diameter begins to decrease after their base, dwindling from $1.25 \mu \mathrm{m}$ to $0.5 \mu \mathrm{m}$ at midlength (Fig. 1), Like antennal sensilla trichodea in other lepidopterans, the sensilla trichodea I possess a non-flexible base; the sensillar shaft bears circumferential cuticular ridges that form a helical pattern over the basal quarter of its length and a more annular pattern over the remaining length of the sensillum. The shaft is perforated by 11 pores $/ \mu \mathrm{m}^{2}$ which form

Table 1. Length, basal width $(\mu \mathrm{m})$, average numbers and percentages of sensilla on a female antenna of Heterobathmia pseuderiocrania (based on 10 antennae) (mean $+/$ - S.D.).

\begin{tabular}{lcccc}
\hline Sensilla & Length & Basalwidth & Numbers & Percentage \\
\hline TrichodeaI & $23,6+/-5,9$ & $1,2+/-0,2$ & $700+/-13,6$ & 41,5 \\
TrichodeaII & $29,9+/-4,6$ & $1,5+/-0,4$ & $364+/-9,3$ & 21,6 \\
Coeloconica & $3,2+/-0,7$ & $1,5+/-0,1$ & $84+/-2,1$ & 5,0 \\
Chaetica & $18,7+/-2,5$ & $1,2+/-0,2$ & $146+/-7,8$ & 8,7 \\
Basiconical & $2,4+/-0,5$ & $0,9+/-0,1$ & $42+/-2,3$ & 2,5 \\
BasiconicalI & $17,5+/-4,3$ & $1,4+/-0,3$ & $112+/-5,1$ & 6,6 \\
Auricillical & $18,3+/-3,4$ & $1,2+/-0,3$ & $70+/-3,2$ & 4,2 \\
AuricillicaII & $8,6+/-0,8$ & $2,4+/-0,5$ & $112+/-2,9$ & 6,6 \\
Böhm'sbristles & $9,3+/-2,7$ & $1,3+/-0,4$ & $55+/-1,7$ & 3,3 \\
\hline
\end{tabular}



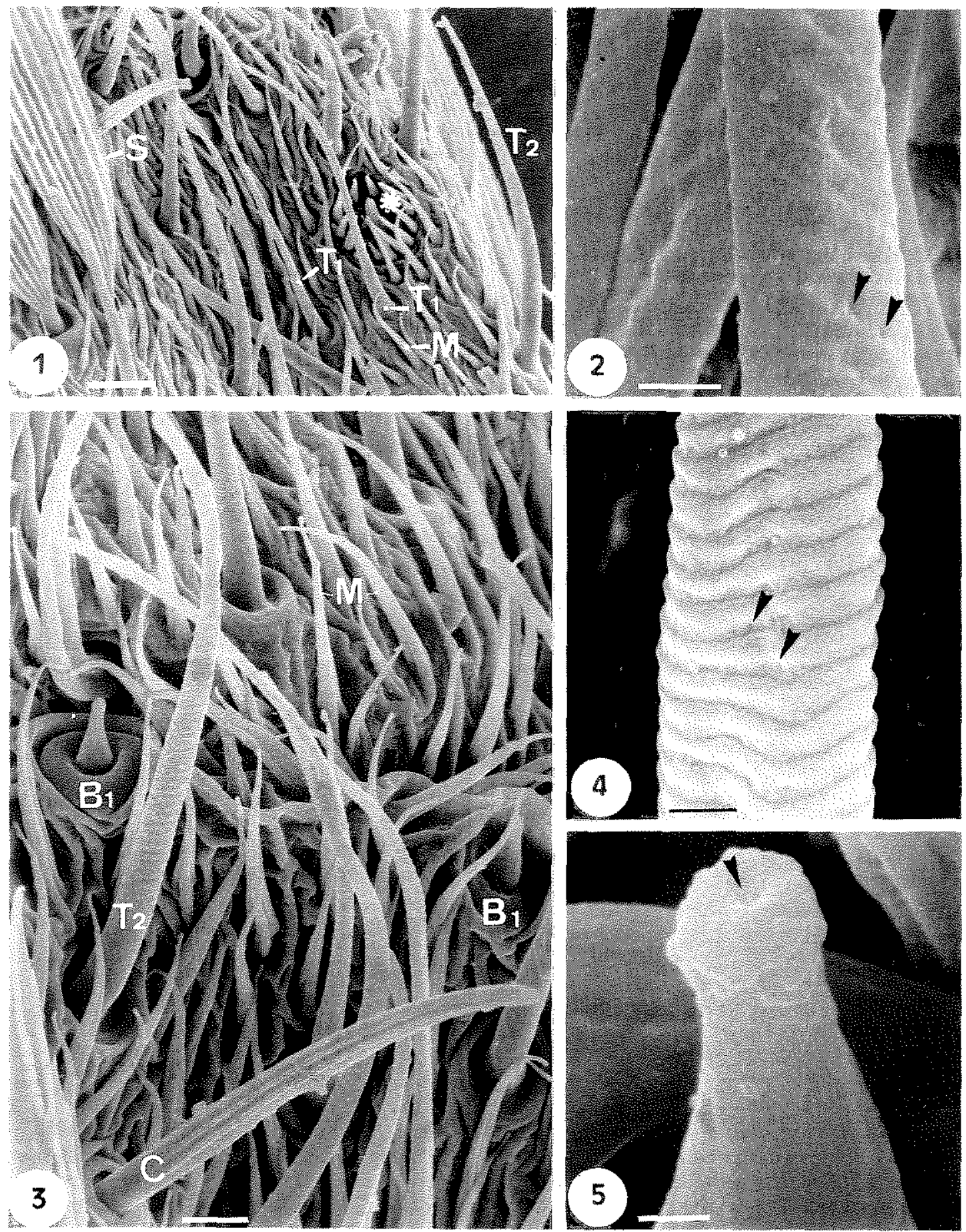

Figs. 1-5. Antenna of Heterobathmia pseuderiocrania, female. 1, Part of a flagellomere showing sensilla trichodea of subtypes I (T1) and II (T2), s. cœloconicum (asterisk), lamellar scales (S) and microtrichia (M). Bar $=5 \mu \mathrm{m}$. 2, detail of 8 . trichodeum I showing pores (arrowheads). Bar $=0.5 \mu \mathrm{m} .3$, sensilla trichodeum (T2), s. chaeticum (C), s. basiconica type I (B1), and numerous microtrichia (M). Bar $=2$ $\mu \mathrm{m} .4$, detail of s. trichodeum II showing pores (arrowheads). Bar $=0.3 \mu \mathrm{m}$. 5, terminal pore of $\mathrm{s}$. basiconicum type I. Bar $=0.2 \mu \mathrm{m}$. 
lines between the cuticular ridges; they occur up to the tip of the sensillum, and their walls are characterised by transversal and sometimes oblique striae (Fig. 2). The sensilla which occupy the whole surface of flagellomeres are generally lined up transversally across the antenna. Their number tends to diminish as they reach the distal flagellomeres; the average is 25 sensilla per flagellomere.

\section{Multiporous sensilla trichodea subtytpe II}

Slightly longer than that of subtype I sensilla, the sensilla trichodea II are thicker than the latter and above all they retain their basal diameter over a considerable length: $1.5 \mu \mathrm{m}$ at the base, it is still as much as $1.25 \mu \mathrm{m}$ at midlength (Fig. 1), At this level, the shaft of the sensillum bears cirm cumferential cuticular ridges that form a circular pattern and are more accentuated than those of the preceding sensilla (Figs. 3,4). The pores are located in a single row along the midline of the ridges and extend to the tip of the sensillum. The wall pore density is estimated at 14 pores $/ \mathrm{mm}^{2}$. Like subtype I sensilla, the subtype II form transversal lines and cover the whole of the ventral face of flagellomeres. Their number reaches 13 per flagellomere. The sensilla trichodea I and II are the most abundant of all sensilla (63\%, Table 1$)$.

\section{Multiporous sensilla coeloconica}

Sensilla coeloconica are composed of a fluted cone, $3 \mu \mathrm{m}$ long, surrounded by a circular fringe of microtrichia of $7.5 \mu \mathrm{m}$ in diameter (Fig. 1., asterisk). They are mostly found latero-distally on each flagellomere, near the scales, and number 2 4 sensilla per flagellomere.

\section{Uniporous sensilla chaetica}

Unlike the sensilla trichodea which are flattened against the antennal integument, sensilla chaetica stand back obliquely or perpendicularly. As a result, they enter with less difficulty into contact with the surrounding substratum. They possess a basal collar, a hair with longitudinal ridges, and a blunt apex (Fig. 3). The terminal pore is always difficult to distinguish with SEM. Sensilla chaetica form a circle at the distal edge of each flagellomere (Fig. 17); they are the only sensilla present on the dorsal face of the antenna. Typically, they constitute two circles on the apical flagellomere (Fig. 16). Their number reaches 5 per flagellomere except on the tip of the antenna (11 sensilla).

\section{Uniporous short sensilla basiconica, subtype I}

These very short sensilla (Table 1) are surrounded by a large alveolus and are provided with a terminal pore (Figs. 3,5 ). There are 1 or 2 of them per flagellomere located in the distal half of the flagellomere. One sensillum basiconicum is often associated with a sensillum coeloconicum (Fig. 15).

\section{Multiporous long sensilla basiconica, subtype II}

Sensilla basiconica II are curved from the base on and possess a peg of variable length $(8+18 \mu \mathrm{m})$ with longitudinal and sinuous ridges (Fig. 7). The wall of the peg is perforated by 18 pores $/ \mu \mathrm{m}^{2}$ distributed in linear ridges along the axis of the sensillum (Fig. 9). The sensilla are located towards the middle of a flagellomere or, more rarely, apically. Their number reaches 3-5 per flagellomere.

\section{Multiporous sensilla auricillica subtype I}

Sensilla auricillica I are long ear-shaped sensilla, comparable to long flattened sensilla basiconica with a sharp tip (Fig. 8). Their length is identical to that of the sensilla basiconica but their diameter, which is $1.2 \mu \mathrm{m}$ at the base, amounts to $1.8 \mu \mathrm{m}$ at midlength. The shaft of the sensillum bears diagonal cuticular ridges forming a herringbone pattern. The ridges fuse together on one side along the length of the sensillum (Fig. 8). The wall pores, whose density is 24 pores $/ \mu \mathrm{m}^{2}$, are located in cuticular depressions and arranged in oblique linear rows in furrows (Fig. 10). Sensilla auricillica are generally situated at the apex of flagellomeres (Fig. 6). They number 2-3 per flagellomere.

\section{Multiporous sensilla auricillica subtype II}

These sensilla are morphologically different from sensilla auricillica I. They have the shape of a thick pointed ear but the apex is sometimes bifid (Fig. 11, lower sensilla). Each sensillar face possesses two deep furrows and are endowed with irregular ridges where the pores are located (Figs. $12,13)$. They are grouped in pairs in the distolateral transition region between ventral and dor. sal faces (Figs. 11, 17). They number generally 4 per flagellomere, except on the apical flagellomere deprived of these sensilla. 

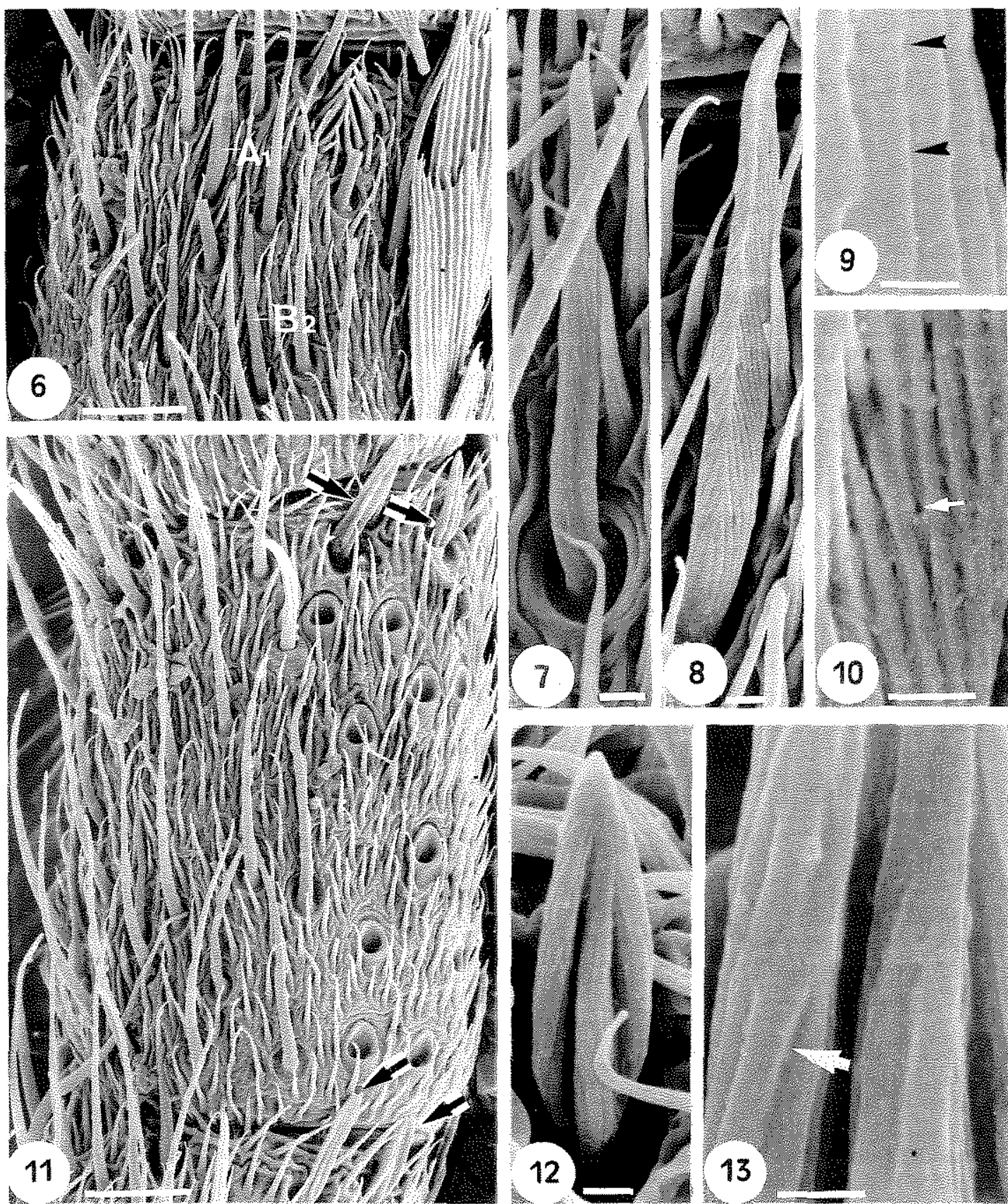

Figs. 6-13. Antenna of Heterobathmia pseuderiocrania, female. 6, apex of a flagellomere showing a s. basiconicum of subtype II (B2), a s. auricillicum of subtype I (A1). Bar $=10 \mu \mathrm{m}$. 7, s. basiconicum II. Bar $=1 \mu \mathrm{m} .8$, s. auricillicum I. Bar $=1 \mu \mathrm{m} .9$, detail of s. basiconicum Il showing pores (arrowheads). Bar $=0.5 \mu \mathrm{m} .10$, detail of $\mathrm{s}$. auricillicum I showing pores. Bar $=0.5 \mu \mathrm{m} .11$, s. auricillica of subtype II (arrows). Bar $=10 \mu \mathrm{m} .12$, s. auricicilicum II. Bar $=1 \mu \mathrm{m} .13$, detail of s. auricillicum II showing location of pores. $\mathrm{Bar}=1 \mu \mathrm{m}$. 

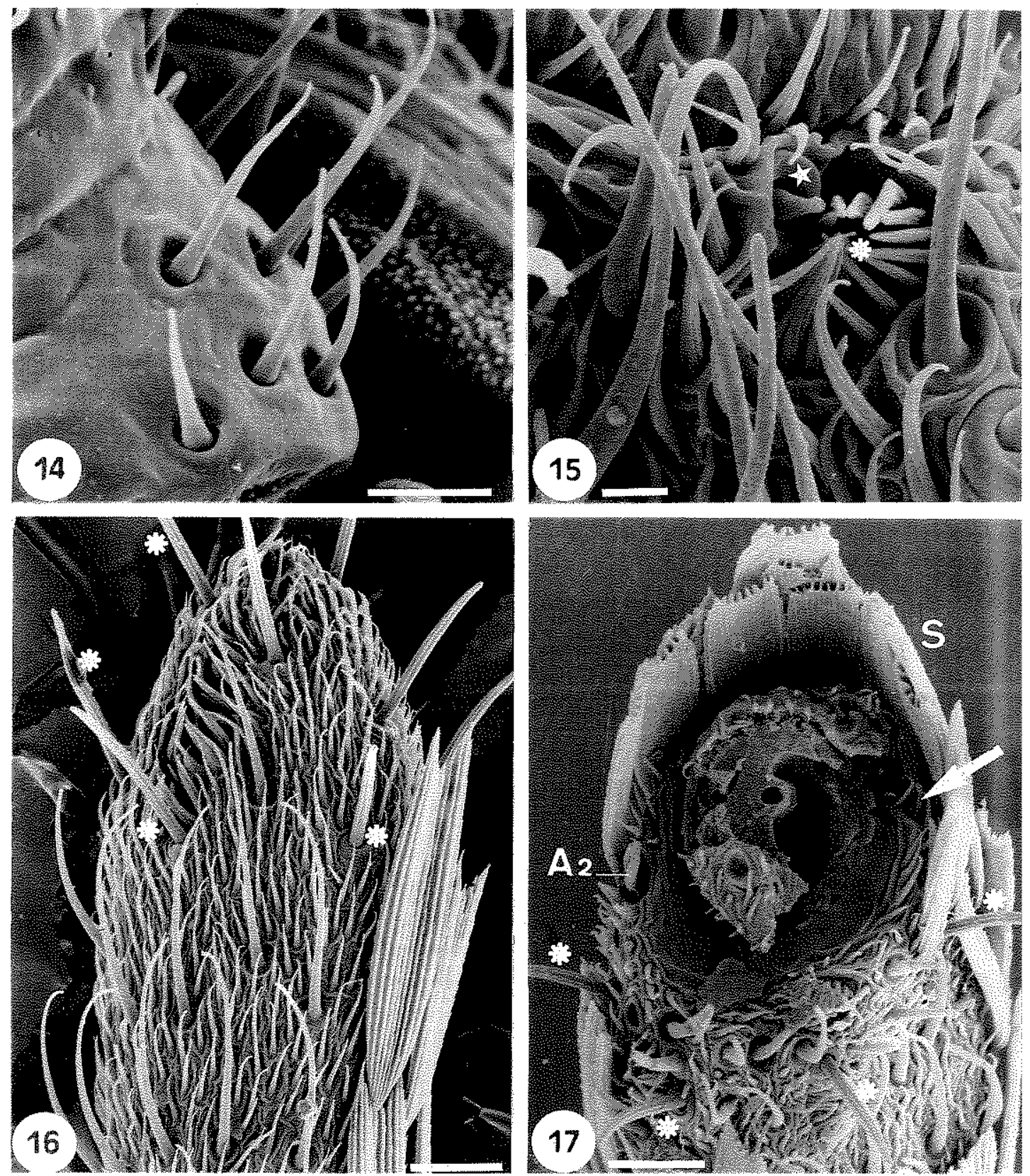

Figs. 14-17. Antenna of Heterobathmia pseuderiocrania, female. Distribution of sensilla. 14, Böhm's bristles at base of scape. Bar $=5 \mu \mathrm{m} .15$, s. basiconicum I (star) near s. cœloconicum (asterisk). Bar $=$ $2 \mu \mathrm{m} .16$, apical segment showing two circles of s. chaetica (asterisks). Bar $=10 \mu \mathrm{m} .17$, Break between two adjacent flagellomeres showing dorsal scales (S) and ventral sensilla : chaetica (asterisks), auricillicum II (A2), basiconicum I (arrow). Bar $=10 \mu \mathrm{m}$.

\section{Aporous Böhm's bristles}

In addition to the sensilla on the surface of the flagellum, there are Böhm's bristles on the scape and pedicel. They are smooth and sharp hairs, always located in clusters (Fig. 14). There are three clusters at the base of the scape (with 10,13 , and 11 sensilla respectively) and two clus- 
ters at the base of the pedicel (with 9 , and 12 sensilla respectively).

\section{DISCUSSION}

The antenna of $H$. pseuderiocrania has similar sensillar types to many other Lepidoptera: sensilla trichodea, basiconica, auricillica, coeloconica, chaetica and Böhm's bristles, but it also reveals many differences which distinguish it.

It possesses no specialized types as the sensilla placodea and sensilla ascoidea of Zeugloptera or the biforked sensilla basiconica of Aglossata which are apomorphous characteristics of these two suborders.

The sensory structures of $H$. pseuderiocrania are close to those of the Glossata, which group together all the higher lepidopterans. These results agree with those of Kristensen $(1984,1999)$ which stated the following: " the Heterobathmiina possess a series of presumedly derived traits which are absent from Zeugloptera and Aglossata, but which do occur in the groundplan of the Glossata, such as the antenna with sensilla auricillica ". Thus, it is with the suborder Heterobathmiina that the sensillar characteristic types of the majority of " higher" Lepidoptera appear for the first time. In particular, the first typical sensilla auricillica (sensilla subtype II) appear with $H$. pseuderiocrania. They have unmodified morphology and localisation over the whole length of the antenna. As in most families of derived Lepidoptera, they are found together on the distal edge of the flagellomeres in the transient region between the scaled face and the unscaled face. Nevertheless, signs of the apparition of sensilla auricillica have recently been described in the Aglossata, in which certain biforked sensilla basiconica have branches which are flattened and spread out, separating in Agathiphaga vitiensis (Faucheux, 1999) or clustered together on the proximal half in A. queenslandensis (Faucheux, 2004). In this suborder, in which the biforked sensilla are distributed over the whole surface of the segments, this poly. morphism is restricted to certain individuals. However, we have observed that this concerns sensilla clustered towards the distal edge of the flagellomeres.

If $H$. pseuderiocrania possesses antennal sensillar types characteristic of the higher Lepidoptera, it is nonetheless distinguished from the latter by several important traits. Indeed, on all the female antennae, two quite different types of sensilla auricillica have been observed. Sensilla auricillica I closely resemble in form and length sensilla basiconica II and may be considered as having evolved from the latter. On the contrary, by their particular form, sensilla auricilica II constitute a new sensory type not to be confused with any other type, appearing for the first time in the Lepidoptera. Their sharp, fluted shape is characteristic of the species studied and perhaps of the suborder Heterobathmina. The presence of two different types of auricillic sensilla in the same species has until now never been mentioned in lepidopterans. In comparison with the other moths, it appears that it is the type II of sensilla auricillica which has been preserved in the more exolved families. On the other hand, type I reappears together with typical sensilla auricillica type II in Noctuidae, considered as one of the most evolved of lepidopteran families, being called "type 3 sensilla trichodea" (Jefferson et al., 1970, «single-walled type 3 " (Hallberg, 1981), "short porous trichodea" (Dongetal., 1980) and "sensilla basiconica type II " (Faucheux, 1990 b, 1997a). Little information exists on the function of multiporous s. auricillica. In the Noctuidae Scoliopterix libatrix, neurons in these sensilla respond to odours of plants which constitute the larval food (Anderson et al., 2000).

Similarly, it is only in H. pseuderiocranic that a sexual dimorphism concerning the sensilla auricilica can be observed. Indeed, type II differs according to sex. The sensilla auricillica represented in the male (Kristensen \& Nielsen, 1979) belong to type II but differ from the female sensilla in several respects: they possess neither the longitudinal folds nor the sharp form of the female sensilla; they are more flattened and the lateral margins are slightly thicker; wider, they assume the form of tennis rackets and are characterised by longitudinal furrows on the external face, the only one visible in SEM. Their apex is sometimes bifid or multifid. It is worth recalling that the female sensilla also, at times, possess a bifid apex. While the female sensilla have a particular form which is specific to them (and identical on the 12 antennae studied), the male sensilla auricillica closely resemble those of both males and females of the Eriocraniidae, Dyseriocrania griseocapitella (Davis, 1978) and of the majority of other Lepidoptera.

Two types of sensilla trichodea occur in female H. pseuderiocrania. We do not know if the situation is the same in the male. This characteristic has not been studied in the Zeugloptera or the Aglossata (Faucheux, 1997b, 1990a). Though infrequent, it has been observed in the economically important species of certain families (Faucheux, 1999). For example, two types of trichoid sensilla have been described in the male and female noctuid moth, Manduca sexta (Lee \& Strausfeld, 
1990; Shields \& Hildebrand, 1999). According to the latter authors, who base their arguments on analogous structures found in the morphologically or physiologically characterized multiporous sensilla trichodea of other female moths, "trichoid, sensilla of female $M$. sexta are likely to be olfactory and to possess sensory cells specialized to respond to plant odours ". Thus it is possible that the two subtypes of sensilla trichodea of $H$. pseuderiocrania perform a similar function to that of the noctuid moth. However, these are speculations which future studies will have to confirm. Contrary to the opinion of Kristensen \& Nielsen. (1979), who declare that « the setae on scapus and pedicellus are not arranged in clusters (Böhm's bristles) ", the proprioceptive Bohm's bristles of the female are grouped according to the characteristic pattern described in Lepidoptera by Sellier (1975). The "short sensilla trichodea set on the entire surface, pointed, with longitudinal striae" described by the latter authors are in fact noninnervated microtrichia. Such spinules have been observed only in primitive families such as the Agathiphagidae (Faucheux, 1990a), the Eriocraniidae and the Acanthopteroctetidae (Davis, 1978) and in the Lophocoronidae, in which they are becoming rare and are associated with a reticulate pattern (unpublished observations).

Sensilla styloconica are absent on the antennae of $H$. pseuderiocrania. This absence has been observed in the Aglossata and the Eriocraniidae but is not specific to the lower Lepidoptera because the Micropterigidae (Zeugloptera) possess them (Faucheux, 1997b). Generally sensilla styloconica in Lepidoptera possess a high stylus and a short sensory cone, but the stylus is absent in some species such as Bombyx mori (Steinbrecht \& Müler, 1991). Reductions in the length of the stylus have been described in a few genera of the same family, as in the Tineidae Trichophaga tapetzella (Faucheux, 1999). It is possible that the uniporous short sensilla basiconica of $H$. pseuderiocrania are a particular type of sensilla styloconica. In that case, the terminal pore would be an ecdysial pore, which has frequently been described in typical sensilla styloconica (Becker, 1978 ). Likewise, in the suborder Aglossata, which does not possess any typical sensilla styloconica, one uniporous short sensillum basiconicum, similar to that of H. pseuderiocrania, is present on each flagellomere, always located near the sensillum coeloconicum at the apex of flagellomeres. Since antennal sensilla styloconica in Lepidoptera perform a hygro-thermoreceptive function, it is probable that the same function is also present in $H$. pseuderiocrania.
In conclusion, $H$. pseuderiocrania possesses a serie of characters which tentatively can be considered as possible autapomorphies of Heterobathmiina, although they need to be verified in other members of this taxon: e.g. (a) the co-existence of two different subtypes of sensilla auricillica in the same species, (b) sensilla auricillica unique to Heterobathmiina and (c) a sexual dimorphism concerning the sensilla auricillica, type II.

\section{ACKNOWLEDGMENTS}

I am grateful to Dr E. S. Nielsen (at his memory) for providing the specimens of Heterobathmia pseuderiocrania, M. Alain Barreau, M. V. Ballardini, M. J. Baudet and Mrs O. Aumaille for their technical assistance.

\section{BIBLIOGRAPHY}

Anderson, P. E. Hallberg \& M. Subchev. 2000. Morphology of antennal sensilla auricillica and their detection of plant volatiles in the herald moth, Scoliopteryx libatrix L. (Lepidoptera: Noctuidae). Arthropod Structure and Development 29: 33-41.

Becker, D. 1978. Elektrophysiologische Untersuchungen zur Feuchterezeption durch die styloconischen Sensillen bei Mamestra brassicae L. (Lepidoptera, Noctuidae). Doctoral Dissertation, Univ. Regensburg $80 \mathrm{pp}$.

Davis, R.D. 1978. A revision of the North American moths of the superfamily Eriocranioidea with the proposal of a new family, Acanthopteroctetidae (Lepidoptera). Smith. Contr. Zool. 251: 1-131.

Dong, N., T.C. Carlysle, H.L. Cromray \& D.H. Habeek. 1980. Morphological studies on the beet armyworm Spodoptera exigua (Hubner) (Lepidoptera : Noctuidae), Tech. Bull. Univ. Fla., Agric. Exp. Stn. Gainsville $\mathrm{n}^{\circ} 816,37 \mathrm{pp}$.

Faucheux, M.t. 1990a. Antennal sensilla in adult Agatiphaga vitiensis Dumbl. and A. queenslandensis Dumbl. (Lepidoptera: Agathiphagidae). Int. d. In sect Morphol. \& Embryol. 19: 257-268.

- 1990 b. External ultrastructure of sensilla on the male and female antennal flagellum of Noctua pronuba L. (Lepidoptera: Noctuidae). Aninls. Soc. Ent. Fr. (N.S.) 26: $173-184$

- 1997a. Structures sensorielles des Noctuelles (Lepidoptera: Noctuidae) et leurs implications phylogénétiques. Bull. Soc. Sc. Nat. Ouest Fr. (N. S.) 19:29.39.

$1997 \mathrm{~b}$. Sensory organs on the antennae of Micropterix calthella L. (Lepidoptera: Micropterigidae). Acta Zoologica (Stockholm) 78: 1-8.

1999. Biodiversité et unité des organes sensoriels des Insectes Lépidoptères. Suppl. H. S. Bull. Soc. Sc. Nat. Ouest Fr. Nantes, 296 pp.

2004. Polymorphisme des sensilles basiconiques bifurquées de l'antenne de l'Agathiphage du 
Queensland, Agathiphaga queenslandensis Dumbleton, 1952 (Lepidoptera: Aglossata, Agathiphagidae). Bull. Soc. Sc. Nat. Ouest Fr. (N.S.) 26: $138-139$,

Hallberg, E. 1981. The structural characteristics of the antennal sensilla of Agrolis segetum (Insecta: Lepidoptera). Cell Tissue Res. 218: 209-218.

Jefferson, R.N., R.E. Rubin, S.U. McFarland \& H.H. Shorey. 1970. Sex pheromones of noctuid moths. XXII. The external morphology of the antennae of Trichoplusia ni, Heliothis zea, Prodenia ornithogalli and Spodoptera exigua. Ann. Ent. Soc. Amer: 63: $1227-1238$.

Kristensen, N. P 1984. Studies on the morphology and systematics of primitive Lepidoptera (Insecta). Steenstrupia 10: 141-191.

- 1997. Early evolution of the Lepidoptera + Trichoptera lineage: phylogeny and the ecological scenario. In: P. Grandcolas (ed.), The Origin of Biodiversity in Insects : Phylogenetic Tests of Evolutionary Scenarios. Mém. Mus. natn. Hist nat. $173: 253-271$

- 1999. The non-glossatan moths. In: N. P. Kristensen (ed.), Part 35. Lepidoptera, Moths and Butterflies. Volume 1: Evolution, Systematics and Biogeography. In: M. Fischer (ed.), Handbuch der Zoologie. Volume IV - Insecta. Walter de Gruyter y Co., Berlin, pp. $41 .-49$.

Kristensen, N.P. \& E.S. Nielsen. 1979. A new subfamily of micropterigid moths from South America. A con" tribution to the morphology and phylogeny of the Micropterigidae, with a generic catalogue of the fam- ily (Lepidoptera: Zeugloptera), Steenstrupia 5: 69. 147.

- 1982. South American micropterigid moths: two new genera of the Sabatinca+group (Lepidoptera: Micropterigidae). Ent. scand. 13: 513-529.

Lee, J.K. \& N.J. Strausfeld. 1990. Structure, distribution and number of surface sensilla and their receptor cells on the olfactory appendage of the male moth Manduca sexta. J. Neurocytol. 19:519-538.

Nieukerken E.J, van \& H. Dop. 1987. Antennal sensory structures in Nepticulidae (Lepidoptera) and their: phylogenetic implications. Z. Zool. Syst. Evolut. forsch. 25: 104-126.

Schneider, D. 1964. Insect antennae. Annu. Rev. Ent. 9 : 103-122.

Sellier, R. 1975. Etude morphologique et topographique en microscopie électronique à balayage des sensilles de Böhm chez les Lépidoptères: essai d'interprétation de leur mode de fonctionnement. C. R. Acad. Sci. Paris, série D. 280:1869-1872.

Shields, V.D.C. \& J.G. Hildebrand. 1999. Fine structure of antennal sensilla of the female sphinx moth, Manduca sexta (Lepidoptera: Sphingidae). I. Trichoid and basiconic sensilla. Can. J. Zool. 77: 290-301.

Steinbrecht, R.A. \& B. MULLLER. 1991. The thermo-f hygrosensitive sensilla of the silkmoth, Bombyx mori: morphological changes after dry- and moistadaptation. Cell Tissue Res. 266: 441-456.

Zacharuk, R.Y. 1985. Antennae and sensilla. In: Kerlut G. A. \& Gilbert L. I. (eds.), Comprehensive Insect Physiology, Biochemistry and Pharmacology (Vol. 6), pp. 1- 69, Pergamon Press, Oxford. 